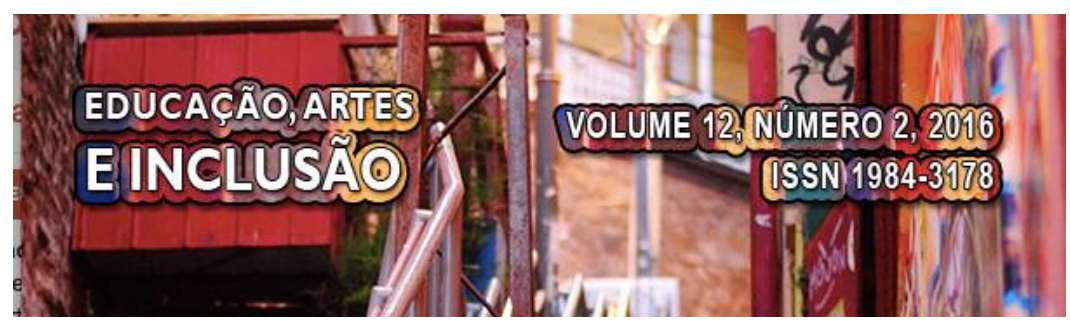

\title{
EDUCAÇÃO PELA ARTE DO GRAFITE EM UMA ESCOLA PÚBLICA: UMA PROPOSTA DE PARTICIPAÇÃO
}

\author{
EDUCATION BY GRAFITTI ART IN A PUBLIC SCHOOL: A \\ PARTICIPATION PURPOSE
}

DOI: http://dx.doi.org/10.5965/1984317812022016141

Luciane Izabel Ferreira Henckemaier - UDESC

\section{RESUMO}

Educar pela arte é uma alternativa instigante, frente ao processo de globalização, onde as tecnologias e meios midiáticos promovem a virtuosidade de expressões, deixando, de certa forma, o trabalho artístico alienado. O fazer artístico deve ser exercitado na escola, de forma que o estudante tenha contato com a experimentação e a prática artística. A abordagem feita neste artigo tem por objetivo elencar questões pertinentes a uma educação pela humanização, em que a escola é protagonista na sua efetivação, e o professor como mediador, numa proposta sócio-histórica. A prática do grafite foi fundamental para exercício da sensibilização e criticidade, oportunizando a manifestação de ideias e mensagens pela arte do grafite, em um ponto de ônibus em frente à Escola de Educação Básica Industrial de Lages, em Lages, Santa Catarina. Este artigo é uma adaptação de um dos capítulos de uma dissertação de Mestrado em Artes Visuais pela Universidade do Estado de Santa Catarina (UDESC), desenvolvida a partir dos relatos da prática de grafite em Lages.

Palavras-chave: educação, escola, prática artística, grafite.

\begin{abstract}
Educating by the art is an exciting alternative against the process of globalization, where technology and media means promoting virtuousness expressions, leaving somewhat, alienated artwork. The artistic work should be trained in school, so that the student has contact with experimentation and artistic practice. The approach taken in this article is intended to list issues pertinent to education for humanization, where the school is protagonist in its execution, and the teacher as a mediator, in a socio-historical propose. The practice of graffiti was essential to exercise awareness and criticality, providing opportunities for the expression of ideas and messages through graffiti art at a bus stop in front of Escola de Educação Básica Industrial de Lages, em Lages, Santa Catarina. This article is an adaptation of one of the chapters of a Master's dissertation in Visual Arts from the Santa Catarina's State University (UDESC), developed from the practice reports of graffiti in Lages.
\end{abstract}

Keywords: education, school, artistic practice, graphite. 


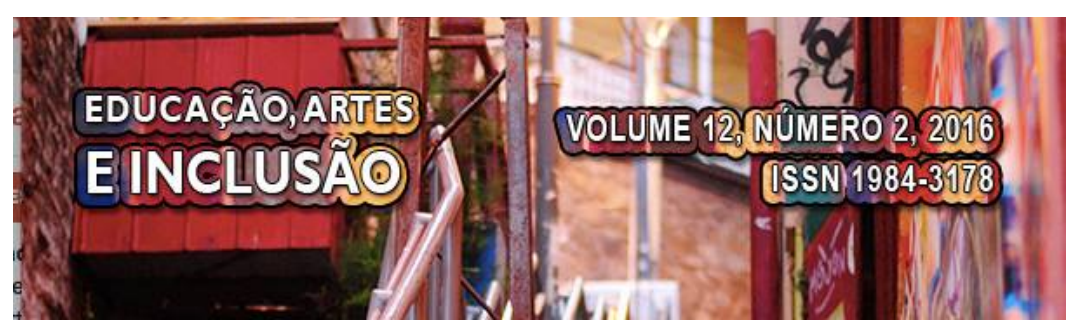

A percepção de Harendt (1994 apud SILVA, 2004, p. 7) propõe que a atividade que transforma o social partindo das ações do homem busca intervir no curso da história. Entende, por este mesmo motivo, que, portanto, é "impossível falar do grafite sem observar que ele surge num contexto urbano particular, com a explícita determinação de provocar uma mudança no curso evolutivo da cidade." (SILVA, 2004, p. 7).

Então, o grafite, podemos dizer, é um desses escritos que resistem à homogeneização, que são não apenas enunciações, mas, sobretudo, engajamento. Aliás, se o próprio exercício afirmativo é algo raro em tempos pós-modernos, é ainda menos frequente, e há algo de muito depressivo nisso, a adesão e o engajamento em alguma ação. (Ibidem, loc. cit.).

Em meio à mobilização social e à produção de conhecimento empreendidas, Furtado (2012) destaca, ainda tratando desta reconfiguração dos laços de pertencimento e interação construídos pelo grafite, que

é a afetividade que mobiliza identidades e a formação de laços entre os sujeitos neste novo contexto das cidades. Esses afetos possibilitam constituir novas relações, mesmo que efêmeras e ao acaso, produzindo outra ordem social. Nesse sentido, o autor afirma uma ética da estética que, atuando como faculdade de sentir em comum configura a convergência de ações, vontades e emoções na constituição de um sentimento de pertença que, segundo o autor, se apresenta no cotidiano das sociedades contemporâneas. (FURTADO, 2012).

Maffesoli (2006 apud Ibidem) argumenta que esse sentimento tribal, de distinção social, característico da pós-modernidade sob o capitalismo, é mais uma forma de criar o pertencimento social, a identidade e o compartilhamento de maneiras de se ver e pensar o mundo. "Na singularização de seus laços, uma certa vontade de estar-junto, de partilhar afetos, de compor tribos." (Ibidem).

Assim, Maffesoli (2006 apud Ibidem) registra que as tribos são caracterizadas como agrupamentos semiestruturados, formados por pessoas que se aproximam pela "identificação comum a rituais e elementos comuns da cultura que expressam valores e estilos de vida, moda, música, lazeres típicos de um espaço-tempo.” Sendo expressão desta urbanidade, estes grupos se constituem em meio a uma sociedade permeada por contradições e transformações constantes. Estratificada, ela protagoniza o fenômeno da "neotribalização". De acordo com Furtado (Idem), 


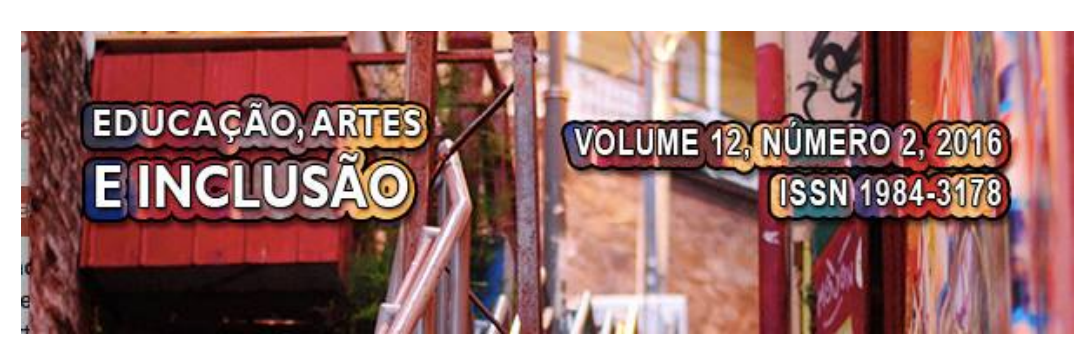

Esta "neotribalização" nas sociedades atuais destaca que o eixo central desses novos agrupamentos está sob a contradição básica e característica da sociedade moderna: auge da massificação social versus a proliferação de microgrupos. Por um lado, o processo de massificação, de homogeneização ou hegemonização das identidades, ou homo-hegemonização, como diria Derrida (2001); por outro, o fenômeno das tribos urbanas, que constituem uma resposta a esse movimento de "desindividualização" dos sujeitos. (Ibidem).

Os agrupamentos presentes no ambiente escolar também são visíveis. Na mesma medida em que os estudantes estão formando a própria personalidade, estão em busca de aceitação social e, para isso, costumam se inserir em algum grupo. Durante o projeto, o grafite foi usado como um elemento de integração entre os sujeitos em busca de um objetivo comum: a expressão nas paredes e localidades do entorno da escola. Além do mais, buscou-se também a desvinculação de uma percepção negativa em alguns casos, que é comum à pichação em relação aos locais onde é praticada. Para isso, o grafite foi a proposta porque

As pichações costumam buscar denegrir o local onde são feitas. Zombam da indiferença das estátuas, da ineficácia dos prédios públicos. O grafite busca criar profundidades nas superfícies planas da cidade. Busca transformar nossa maneira de enxergar. (SILVA, 2004, p. 5)

Também interessa notar que a atividade em grupo mostrou que cada integrante foi fundamental. Expuseram suas próprias singularidades e também negociaram com as diferentes maneiras de pensar dos outros integrantes - tudo em razão de um mesmo projeto comum. Cada um assumiu uma posição, ao mesmo tempo em que todos construíram a prática, "uma atividade social, histórica, livre, criativa, autocriativa, por meio da qual o ser humano cria e transforma o seu mundo e a si mesmo." (FURTADO, 2012).

Levando em conta estas relações, o sujeito interpreta sua posição social, “dá sentido ao conjunto das experiências que vivencia, faz escolhas, age na realidade: a forma como ele se constrói e é construído socialmente, como se representa como sujeito, é fruto desses múltiplos processos." (DAYRELL, 2002, p. 121 apud Ibidem).

A atividade, deste ponto de vista, foi realizada com o intuito de autoconstrução, de contestação, de engajamento em uma causa, que, necessariamente, incentivou o desenvolvimento do pensamento crítico para sua efetivação: e o local de concretização deste projeto, nesta pesquisa, foi a escola. 


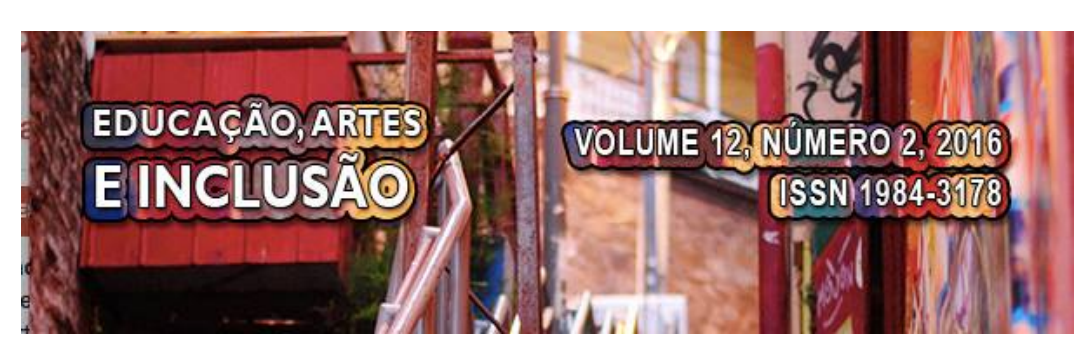

Essas raízes, perpetuadas ao longo dos anos, acompanham a cidade desde a fundação, registrada em 1766. Antes disso, seu território já serviu de caminho para os tropeiros que iam do Rio Grande do Sul para São Paulo, para vender gado para paulistas e mineiros. Juntamente com o gado, os tropeiros traziam consigo a cultura das lidas campeiras e outros costumes gauchescos.

Uma das maiores cidades de Santa Catarina, com extensão territorial de $2629,8 \mathrm{~km}^{2}$ e aproximadamente 156 mil habitantes (IBGE, 2010), Lages é a capital do pinhão. Tem atrativos como as fronteiras das fazendas de turismo rural, com eventos culturais, Bienal do Livro, Festival de Teatro e a Festa Nacional do Pinhão, eventos culturais de grande participação do público. A arquitetura contempla o estilo Art Déco, nos prédios monumentais, como a Catedral Diocesana e a Prefeitura Municipal, no centro da cidade, bem como em Colégios, Museus e outras construções.

Lages tem um contexto social característico de uma cidade provinciana, onde praticamente não existe a cultura da arte de rua, que envolve outros modos de expressão e contempla o grafite. Em alguns espaços, como muros e outros locais, existem garatujas e pichações feitas sem autorização, o que, de certa forma, contribui para a negação dos mesmos e do grafite como arte.

Por outro lado, o grafite dificilmente é visto no ambiente urbano da cidade. Também por este motivo, coube ao ambiente escolar, em uma instituição em especial, fomentar a discussão e a realização da arte pública do grafite de dentro das salas de aula para o cotidiano da cidade: a Escola de Educação Básica Industrial de Lages.

\section{INDUSTRIAL DE LAGES: ENTRELAÇADO ÀS RAÍZES HISTÓRICAS}

Fundada há 51 anos, a escola situa-se à Avenida Dom Pedro II, número 2555, no Bairro Vila Nova, em Lages, na serra catarinense. O espaço físico, que só agora passa pela primeira reforma geral desde a inauguração, contempla uma estrutura de grandes dimensões, composta por um ginásio, campo de futebol, área verde, horta escolar e oficina mecânica tendo em vista o ensino profissionalizante, que originou o nome da escola. Instituição tradicional na cidade, a escola integra a rede pública estadual de ensino.

Realizar um projeto que envolveu não só o ofício, mas a arte como construção de conhecimento e de humanização dos sentidos, foi o incentivo propulsor que motivou este 


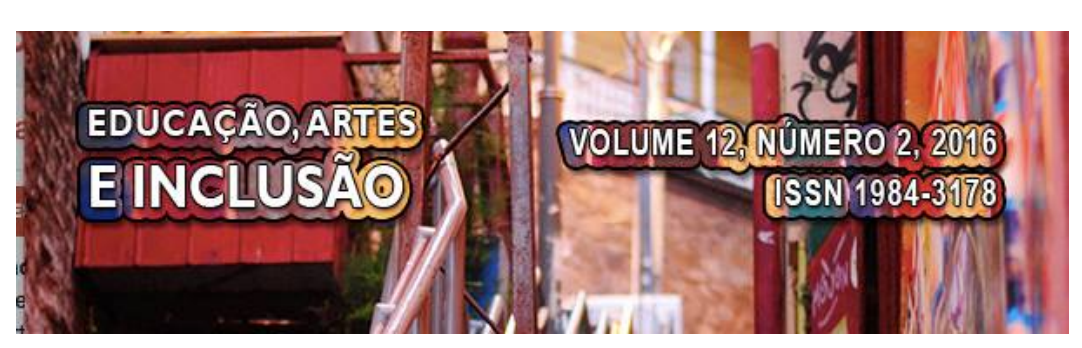

Por isso, compartilhar saberes no contexto da escola se fez necessário: As atividades, realizadas durante um bimestre, iniciaram com a fundamentação teórica para com os estudantes: fez-se, para tanto, um resgate de informações pertinentes ao desenvolvimento da arte em paredes - aproximadamente um mês de aulas foi destinado à discussão e mediação de conceitos. Desde a pré-história da arte, com as pinturas rupestres, passando pela arte mural no período das primeiras civilizações, pelos afrescos renascentistas, principais nomes de muralistas que ficaram marcados na história, tanto universal, quanto na arte brasileira.

O caráter transgressor do grafite e a sua não-legitimidade foram abordados e contextualizados, na tentativa de criar um fio condutor para a melhor compreensão da linguagem expressiva que utiliza suportes diferenciados, como paredes, muros, túneis, pontos de ônibus, ou até recentemente em galerias - ressaltando-se, porém, que os grafites são, principalmente, feitos em espaços públicos gratuitos. Percebeu-se que o grafite é um tipo de linguagem bem aceito pelos estudantes. Tem algo que cativa, atrai a atenção e tem significado efetivo na expressão deles.

Dois anos após a experiência realizada na biblioteca, a necessidade de ganhar o espaço público tornou-se realidade. A interação entre estes ambientes foi um ingrediente importante para realização do grafite em dois pontos de ônibus situados em frente à escola. A realização do grafite, vale destacar, ocorreu em 2012. É deste estopim que surge a proposta desta pesquisa: com a intervenção no espaço urbano, partindo do aprendizado e da educação em sala de aula, com a participação efetiva dos estudantes e da comunidade escolar.

Assim, mesmo não conhecendo partes do processo da grafitagem, os estudantes se sentiram estimulados e dividiram-se em grupos para a realização das tarefas. Alguns fizeram a limpeza dos pontos de ônibus; o servente da escola se habilitou a fazer a pintura de fundo do suporte; outros se encarregaram de arrecadar tintas para pintar partes do ponto de ônibus e outros colaboraram na pintura propriamente dita.

Foram diversos os ambientes escolhidos para a realização do projeto. Para a apresentação da temática, o espaço da sala de artes foi fundamental: usado para fazer os desenhos e projetos que poderiam servir de pano de fundo para as pinturas dos pontos de ônibus.

A escolha deles, neste sentido, foi um passo "fora da escola", pois em outras oportunidades, grafites e pintura em mural foram feitos, só que dentro do espaço escolar. Um espaço que anteriormente tinha registros de palavrões, sujeira e cartazes foi percebido como 
